\title{
Strength Behavior of M25 Grade Concrete Mixed With Two Artificial Fibers in Both Curing and Without Curing Condition
}

\author{
G. Gowri Sankara Rao, Saikrishna Ippili, Chintagunti.Vasudeva
}

\begin{abstract}
Beton is a construction material that consists of cement mixtures, fine added gross aggregates, and water that can spread or pour into the molds and form a stone like mass when hardened. In this design, two synthetic fibers are being applied to the concrete and the compressive strengths of the concrete are compared. Synthetic and stainless steel fibers can be used in concrete and can be tested for the effect of these fibers on concrete. Fiber-containing concrete improves service life and has a positive impact on social life and social economy. The compression charge is so high in the compression that the total essentially holds. Beton is low in heat, so we can increase its tensile strength by incorporating these fibres. The cement holding the aggregate in place could break down to allow the structural failures since it has poor strength. It was investigated. The research also focuses on the comparative study between fiber-added concrete and traditional concrete structural capacity. This plan contrasts the strength of concrete together with the compressive strength of traditional concrete of grade M25 with both a curing and non-curing condition such as fiber cement fibers $0,5 \%, 1,0 \%$, and $1,5 \%$, of synthetic fibers such as synthesis and metal. The strength of synthetic concrete fibers is equivalent to the strength of steel concrete fibers.
\end{abstract}

Keywords: Compressive Strength, Conventional Concrete, Different Fibers, Fiber Cement Ratio.

\section{INTRODUCTION}

In addition, during the last two decades concrete technologies have evolved at a fast pace, and product quality has improved significantly. It's hard to maintain concrete strength and increase its longevity, so adding waste fibers is a cost-effective way to increase horizontal strength. The addition of fibers to the concrete mix provides a product with an improved compressive strength, tensile capacity and other advantages, such as increased ductility and decreased stainless steel compliance requirements. Fibre Reinforced Concrete is a concrete. It comprises small, isolated, randomly directed fibers. For specific fibrous materials, the characteristics of the fiber reinforced concrete vary. The structural strength of concrete increases through fibers.

Beton is a breakable material and if any refurbishment applied in the concrete matrix is not cracked it is redundant, but it fatigues $90 \%$ of the time, showing evidence of cracking, but is difficult to predict, however how much crack

Revised Version Manuscript Received on September 13, 2019.

Parul Sood, Department of Computer Science and Engineering Chandigarh University Gharuan, India. E-mail: Parule7206@ cumail.in is determined and managed by reinforcement. In the allocation of these stresses and how important the crack widths are, what kind of reinforcement and the material properties of reinforcing play a major role. Ideally, this plan will provide a better understanding of the fiber to be used for a particular application. It is also worth pointing out that fibre technology is constantly evolving and that new and innovative goods, techniques and methods are always being created for putting reinforced concrete.

That reinforcements and material properties of reinforcing play an important role in determining these stresses and the importance of break widths. This project hopefully provides a better comprehension of the fiber used for a specific application. Fiber engineering is also continually evolving and new, creative materials, techniques and procedures for the construction of reinforced concrete will always be developed. A fine or short fibre, for example, shortened glass fibre, is only useful for the first hours after the concrete has been pouring in (lowering cracking when strengthening the concrete), but does not improve the tensile strength of the concrete.

\section{OBJECTIVE}

Generally fiber is used to monitor the cracking and drying shrinkage of plastic shrinkage in concrete. These also reduce concrete permeability and thereby reduce water bleeding. Those fibers have a higher impact, abrasion, and concrete shattering resistance. The bending strength of concrete does not generally increase fibers, so that moment-resistant and structural steel reinforcement cannot be replaced.

- Generally fiber is used to monitor the cracking and drying

shrinkage of plastic shrinkage in concrete. These also reduce concrete permeability and thereby reduce water bleeding. Those fibers have a higher impact, abrasion, and concrete shattering resistance. The bending strength of concrete does not generally increase fibers, so that moment-resistant and structural steel reinforcement cannot be replaced.

- This increases the concrete's tensile strength.

- The intrinsic porosity of the solution reduces air voids and water voids.

- It increases the durability of the concrete.

- Fibber's like graphite and glass are very resistant to cramping, while most resins 
do not do the same.

The orientation and fiber's density, therefore, have a major impact on rebars'/tendons ' creeping results.

\section{METHODOLOGY AND MATERIALS USED IN PROJECT}

\subsection{METHODOLOGY}

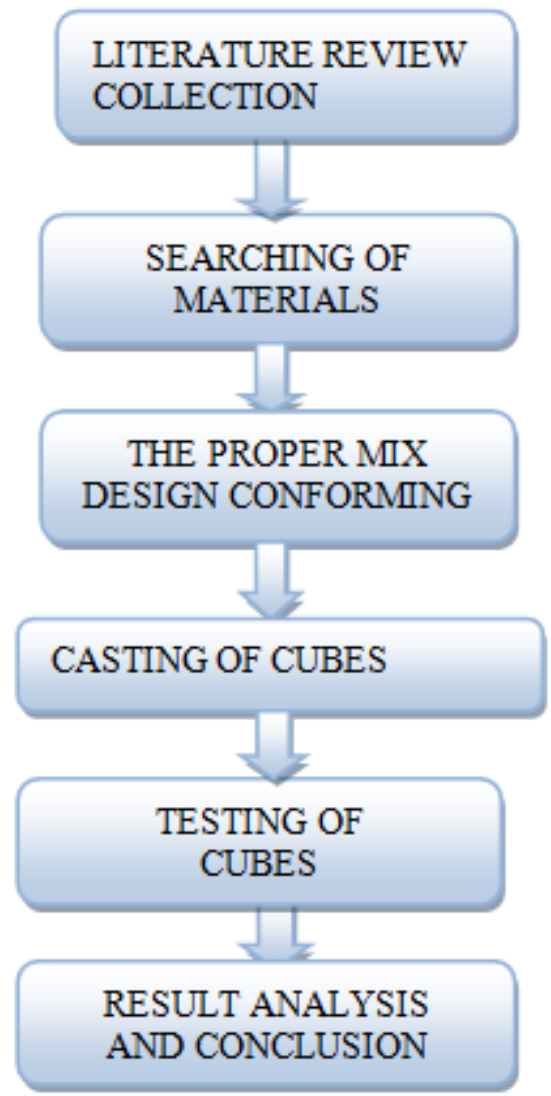

\subsection{MATERIALS FOR THE PROJECT}

\subsubsection{CEMENT}

The most common use in Portland cement is in the manufacture of cement a composite material composed of aggregates (Gravel and Sand), cement and water. In a process known as calcinations, a carbon dioxide molecule is released from calcium carbonates to form calcinations through heating calcine (calcium carbonates) with other materials, e.g. clay). The resulting hard material, known as a "clinker," is then ground into a powder with a small quantity of gypsum for the manufacture of "normal Portland cement."

\subsubsection{COARSE AGGREGATE}

The coarse aggregates consist of particles larger than 4.74 $\mathrm{mm}$, which typically range in size from $9.5 \mathrm{~mm}$ to $37.5 \mathrm{~mm}$. These can be primary and secondary sources, and can be reused. Whether land-marine-won primary or virgin composite. Gravel is a coarse sea-won aggregate; gravel and crushed stone are earth-won coarse aggregates. The gravel is mostly used in concrete with crushed pillars that make up most of the rest of the coarse aggregates.

\subsubsection{FINE AGGREGATE}

The primary sands collected from the land and marine environment are fine aggregations. Fine aggregates are usually made of natural sand or broken rock, the bulk of which move through a $4.75 \mathrm{~mm}$ sieve, as these can be made from primary, secondary or recycled sources with the coarse aggregate.

\subsubsection{SYNTHETIC FIBERS}

This helps prevent cracking because the heat and cold do not spread. Synthetic fibers are composed of small molecular synthesized polymers. The substances used to produce such fibres, such as petroleum chemicals and petrochemicals, are raw materials. The materials are polymerised into a long linear chemistry that binds two neighboring atoms of carbon. The manufacture of different types of synthetic fibre is based on different chemical compounds.

\subsubsection{STEEL FIBERS}

Many widely used fibres are metal fibres. Rund fibers may vary from $0.25 \mathrm{~mm}$ to $0.75 \mathrm{~mm}$ in diameters \& width. In some applications, steel mixed in concrete fibers can provide an alternative to the supply of standard steel bars or soiled cloth. The model continues for many years and is used in a few applications: Adding the steel fibers to the concrete increases the cracking strength of the concrete (or the ductility).

\section{MIX DESIGN}
a) Grade designation : M25
b) Type of cement : opc 53 grade
g) Test data for materials
Specific gravity:
a) Cement :3.02
b) Coarse aggregate :2.71
c) Fine aggregate:2.72

c) Maximum nominal size of aggregate : $20 \mathrm{~mm}$

d) Minimum cement content : $320 \mathrm{~kg} / \mathrm{m} 3$

e) Maximum water cement ratio : 0.47

f) Maximum cement content : $450 \mathrm{~kg} / \mathrm{m} 3$

\begin{tabular}{|l|l|c|c|c|}
\hline $\begin{array}{l}\text { Ingredient } \\
\mathrm{s}\end{array}$ & $\begin{array}{l}\text { Cemen } \\
\mathrm{t}\end{array}$ & $\begin{array}{l}\text { Fine } \\
\text { aggregat } \\
\mathrm{e}\end{array}$ & $\begin{array}{l}\text { Coarse } \\
\text { aggregat } \\
\mathrm{e}\end{array}$ & $\begin{array}{c}\mathrm{W} / \mathrm{C} \\
\text { ratio }\end{array}$ \\
\hline Ratio & 1 & 1.81 & 2.49 & 0.47 \\
\hline
\end{tabular}

\section{TEST RESULTS AND ANALYSIS}

\subsection{COMPRESSIVE STRENGTH TEST:}

Take concrete (sent to the laboratory) measurements. The cross-sectional area 
(mm2 unit) is measured and placed in the journal. For each test, do the same. Place a concrete test in the middle of the loading area. Click the lever to decrease the piston to the concrete rim. Do not load now. Now don't load. To enter the concrete sample, simply place the piston. The pillar is now over the specimen. Take the heel in the lock. Begin the compression test with a zero button on the board screen.

Increase the pressure by turning the valve in the opposite direction; change the pressure on the piston to the compression quality of concrete. Perform without shock the load slowly. Watch the same video. Stop applying load when it begins to break. Register the last paper load on the display screen of your computer. Remove the broken concrete from the unit if the piston is back into its socket. Calculate the force of the compression result obtained from the testing machine which is the last load to crack the concrete requirement. Concrete compression is provided by load per area of the sample.

Table.5.1(a) : Values of compressive strength of M25 grade concrete with different percentage of synthetic

fiber for 7,28,56 and 90 days at curing condition.

\begin{tabular}{|c|l|l|l|l|}
\hline $\begin{array}{l}\text { \% Of } \\
\text { Fiber }\end{array}$ & 7 days & 28 days & 56 days & 90days \\
\hline 0 & 33.59 & 32.28 & 40.55 & 45.80 \\
\hline 0.5 & 34.69 & 43.29 & 43.52 & 47.26 \\
\hline 1 & 31.04 & 43.15 & 35.81 & 44.54 \\
\hline 1.5 & 30.94 & 35.66 & 39.41 & 45.23 \\
\hline
\end{tabular}

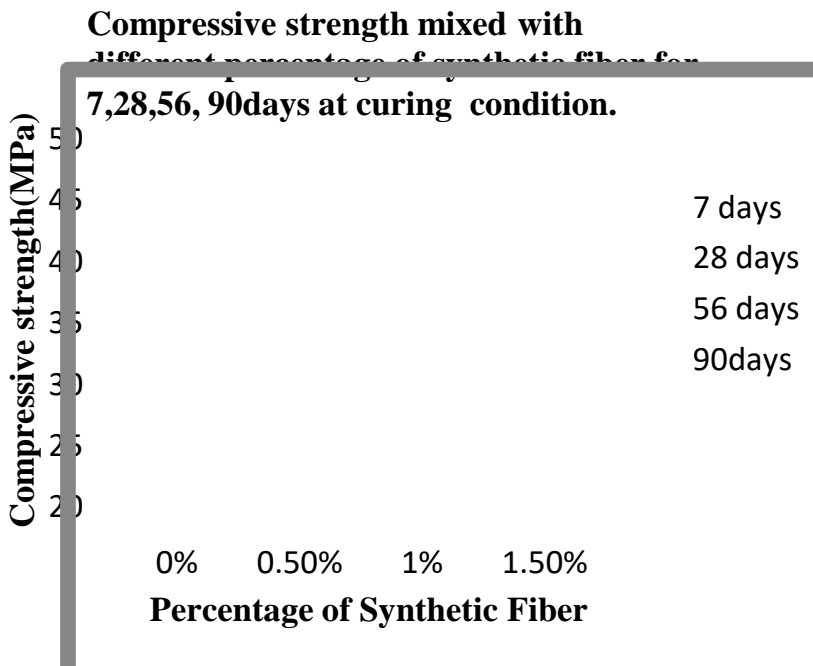

Graph 5.1 compressive strength mixed with different percentage of synthetic fiber for 7,28,56 and 90 days at curing condition.

Description of Result:

- The graph shows that the compressive strength increases by $3.27 \%$, from $0 \%$ to $0.5 \%$ and decreases by $7.59 \%, 7.89 \%$ at $1 \%$ and $1.5 \%$ at 7 days in the treatment phase.
- The intensity of compressive goods increases $34.10 \%$ in 28 days, $33.67 \%$ opposed by $10.47 \%$ to $0.5 \%, 1 \%$ and $1.5 \%$.

- The intensity of compressive goods increases $34.10 \%$ in 28 days, $33.67 \%$ opposed by $10.47 \%$ to $0.5 \%, 1 \%$ and $1.5 \%$.

- Over 90 days the power of compressors rises by $3.19 \%$, from $0 \%$ to $0.5 \%$ and falls then by $2.75 \%, 1.24 \%$ to $1 \%$ and $1.5 \%$.

Table5.1(b) : Values of compressive strength of M25 grade concrete with different percentage of synthetic fiber for 7,28,56 and 90 days at without curing condition.

\begin{tabular}{|c|l|l|l|l|}
\hline \% of fiber & $\mathbf{7}$ days & $\mathbf{2 8}$ days & $\mathbf{5 6}$ days & 90days \\
\hline 0 & 29.11 & 28.80 & 33.53 & 35.19 \\
\hline 0.5 & 29.94 & 38.00 & 38.76 & 39.33 \\
\hline 1 & 28.52 & 33.49 & 33.63 & 36.75 \\
\hline 1.5 & 27.51 & 32.07 & 34.61 & 35.40 \\
\hline
\end{tabular}

Compressive strength mixed with

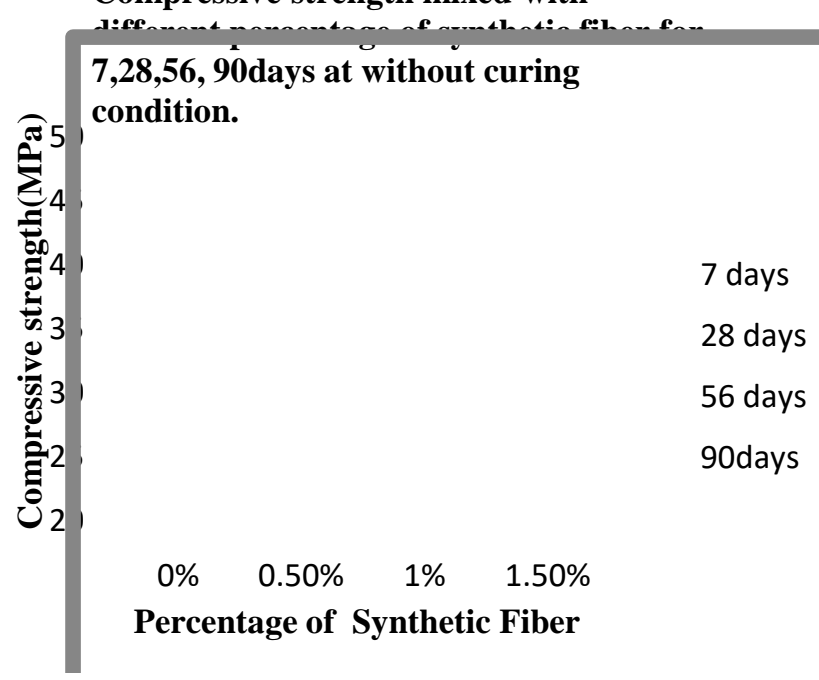

Graph 5.2 compressive strength mixed with different percentage of synthetic fiber for 7,28,56 and 90 days at without curing condition.

Description of Result:

- The graph shows that the compressive force rises by $2.85 \%$, from $0 \%$ to $0.5 \%$, then decreases by $2.03 \%, 5.5 \%$ by $1 \%$, and $1.5 \%$ over 7 days.

- In 28 days, the output of compressed goods rises by $34.11 \%, 33.67 \%, 10.47 \%$, compared to $0.5 \%, 1.5 \%$ and $0.5 \%$.

- The intensity of compressive goods is increased by $15.60 \%$ in 56 days, $0.3 \%, 3.22 \%$ compared to $0.5 \%, 1 \%$ and $1.5 \%$, respectively.

- The intensity of compressive goods is increased by $15.60 \%$ in 56 days, $0.3 \%, 3.22 \%$ compared to $0.5 \%, 1 \%$ and $1.5 \%$, respectively.

Table5.1(c) : Values of compressive strength of M25 grade concrete with different percentage of steel fiber for $\mathbf{7 , 2 8 , 5 6}$ and 90 days at curing condition.

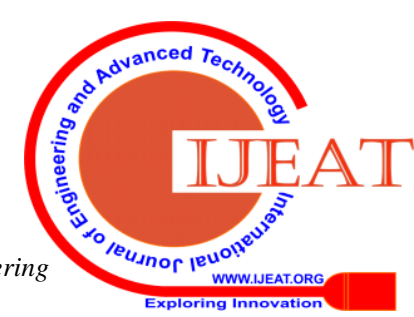




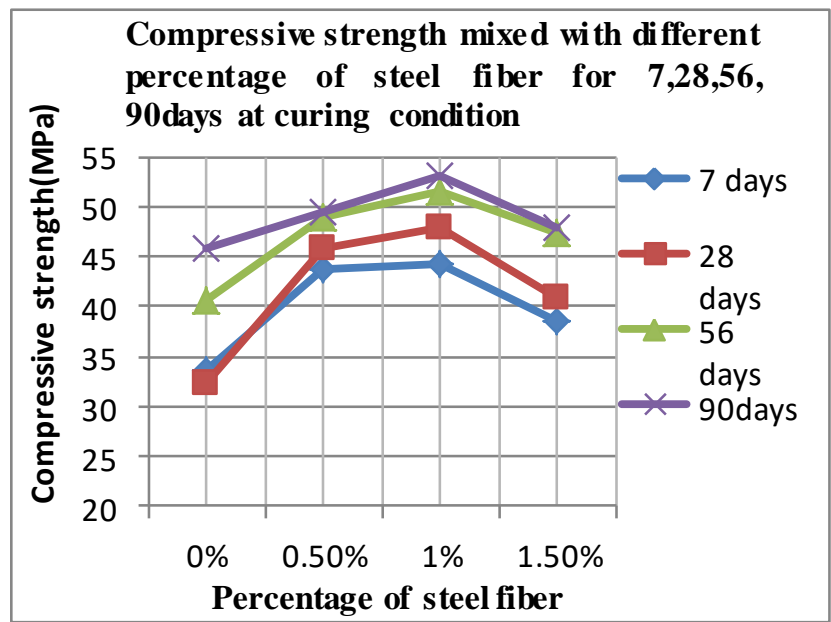

Graph 5.3 compressive strength mixed with different percentage of steel fiber for 7,28,56 and 90 days at curing condition.

Description of Result:

- The diagram showed that the compression force increased by $29.98 \%, 32 \%, 14.65 \%$ versus $0 \%$ to $0.5 \%, 1 \%$ and $1.5 \%$, compressive force increased from 0 to $1 \%$ and then decreased by $1.5 \%$ over 7 days. In addition, compressive resistance increased by $0 \%$ to $1 \%$.

- For two-day compressive strength is $41.67 \%, 48.82 \%$, $26.55 \%$ compared to $0.5 \% 1,1 \%$ and $1.5 \%$. Compressive force is increased from $0 \%$ to $1 \%$, accompanied by decreases of $1.5 \%$. Compressive strength increases by 28 days,

- In 56 days the frequency of the compression increases $20.62 \%, 26.91 \%, 16.74 \%$, compared to $0 \%$ to $0.5 \%, 1 \%$ and $1.5 \%$. The compressive force raises the order from $0 \%$ to $1 \%$ and then the order is decreased.

- Compressive strength increases by $8.1 \%$ in 90 days, $15.98 \%, 4.43 \%$ compared to $0 \%$ to $0.5 \%, 1 \%$ and $1.5 \%$. Compressive strength levels are increased by $0 \%$ and then decreases order from $0 \%$ to $1 \%$.

Table5.1(d) : Values of compressive strength of M25 grade concrete with different percentage of steel fiber for

7,28,56 and 90 days at without curing condition.

\begin{tabular}{|c|l|l|l|l|}
\hline \% of fiber & 7 days & 28 days & 56 days & 90days \\
\hline 0 & 29.11 & 28.80 & 33.53 & 35.19 \\
\hline 0.5 & 40.47 & 42.71 & 47.99 & 48.66 \\
\hline 1 & 41.27 & 41.62 & 42.07 & 42.99 \\
\hline 1.5 & 36.83 & 37.39 & 36.48 & 43.19 \\
\hline
\end{tabular}

\begin{tabular}{|c|l|l|l|l|}
\hline \% of fiber & $\mathbf{7}$ days & 28 days & 56 days & 90days \\
\hline 0 & 33.59 & 32.28 & 40.55 & 45.80 \\
\hline 0.5 & 43.66 & 45.73 & 48.91 & 49.51 \\
\hline 1 & 44.34 & 48.04 & 51.46 & 53.12 \\
\hline 1.5 & 38.51 & 40.85 & 47.34 & 47.83 \\
\hline
\end{tabular}

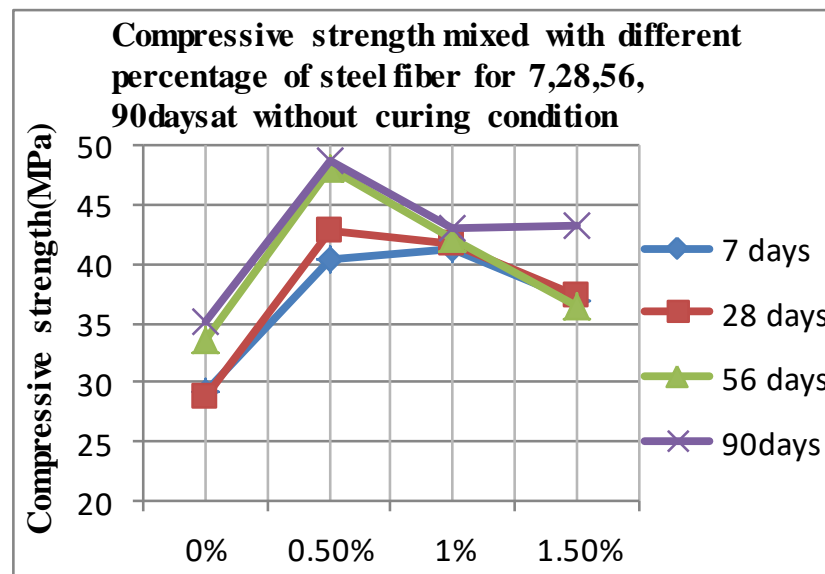

Percentage of Steel Fiber

Graph 5.4 compressive strength mixed with different percentage of steel fiber for 7,28,56 and 90 days at without curing condition.

Description of Result:

- On the graph, compression strength is increased by $39,02 \%, 41,77 \%, 26,52 \%$ versus $0,5 \%, 1 \%$ and $1.5 \%$. Compression strength increases order from $0 \%$ to $1 \%$ and decreases at $1.5 \%$ of 7 days .. Compression strength increases from $0 \%$ to $1.5 \%$.

- In this graph, the frequency of the compression is increased by $39,02 \%, 41,77 \%, 26,52 \%$ vs $0,5 \%, 1 \%$ and $1.5 \%$. The intensity of compression increases order from $0 \%$ to $1 \%$ and decreases by $1.5 \%$ for 7 days. The frequency of compression increases from 0 to $1.5 \%$.

- In 56 days compression capacity increases 43.12, 25.47, $3.8 \%$ compared to $0 \%$ to $0.5 \%, 1 \%$ and $1.5 \%$. Compressive force raises order from $0 \%$ to $0.5 \%$, followed by reductions in order.

- In 90 days, the frequency of the compression is growing $38.28 \%, 22.16 \%, 22.73 \%$, compared with $0 \%$ to $0.5 \%, 1 \%$ and $1.5 \%$. Compressible intensity increases by $0 \%$ to $0.5 \%$, and then deepens.

\section{CONCLUSION:}

- For 7 days, the effects of testing are both cured and without cured, the compression capacity of the synthetic fibers rises from traditional fiber concrete to $0,5 \%$ and the weight is increasing. Yet concrete in steel fibers offers up to $1 \%$ more strength than other fibre-concrete materials and then falls to $1,5 \%$.

- On the basis of 28-day test results, the compressive strength increases from traditional to $0.5 \%$ of the fibre, both for curing and 
without curing conditions. The compressive strength of stainless steell fiber in the curing conditions of concrete is increased up to 1 percent and decreased, but the compressive strength of stainless steel fibers is increased up to 0.5 percent and decreased afterwards. The strength of the concrete curing state rises up to $1 \%$ and then decreases, but the intensity increases to $0.5 \%$ in no cure condition and then decreases in order.

- On the basis of 90 days of concrete fiber testing, a synthetic fiber concrete's compressive strength increases from traditional concrete to $0,5 \%$ and then decreases during curing. In the absence of curing conditions the strength of synthetic fibre-concrete rises from normal concrete to $1.5 \%$. In the condition of the stainless steel fiber treatment system, compressive strength increases and then decreases from traditional fiber concrete, but compressive strength increases from conventional fiber concrete in an untreatable state to $0.5 \%$ and then further decreases from $1 \%$ to $1.5 \%$ fiber concrete compressive strength from 0.5 to $1 \%$.

\section{REFERENCES}

1. Cominoli, L., G. A. Plizzari, and P. Massinari. "Synthetic Fibre Reinforced Concrete for precast panels: material characterization and experimental study."

2. Vasudev, R., and B. G. Vishnuram. "Experimental Studies of the Application of Turn Steel Scraps as Fibres in Concrete-A Rehabilitative Approach." International Journal of Engineering and Technology (IJET), ISSN: 0975-4024

3. Murali, G., et al. "Influence of steel fibre on concrete." Prism 4 (20

4. Lublóy, Éva Majorosné. "The Influence of Concrete Strength on the Effect of Synthetic Fibres on Fire Resistance." Periodica Polytechnica Civil Engineering 62.1 (2018): 136-142

5. Arunakanthi, E., and JD Chaitanya Kumar. "Experimental Studies on Fiber Reinforced Concrete (FRC)." International Journal of Civil Engineering and Technology 7.5 (2016): 329-336.

6. Khadake, S. N., and C. G. Konapure. "An investigation of steel fiber reinforced concrete with fly ash." J Mech Civ Eng 4.5 (2012): 01-5.

7. Hasan, M. J., M. Afroz, and H. M. I. Mahmud. "An experimenta investigation on mechanical behavior of macro synthetic fiber reinforced concrete." International Journal of Civil and Environmental Engineering 11.3 (2011): 18-23.

8. Cominoli, L., C. Failla, and G. Plizzari. "Steel and synthetic fibres for enhancing concrete toughness and shrinkage behaviour." International Conference of Sustainable Construction Materials and Technologies. Coventry, United Kingdom. 2007.

9. Deng, Zongcai, and Jianhui Li. "Mechanical behaviors of concrete combined with steel and synthetic macro-fibers." International Journal of Physical Sciences 1.2 (2006): 57-66.

\section{AUTHORS PROFILE}

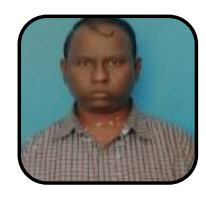

G.GOWRI GOWRI SANKARA RAO, D.C.E., A.M.I.E. Civil, M.Tech (St.),( Ph.D.),Associate Professor, Department of Civil Engineering, Aditya Institute of Technology And Management, ANDHRA PRADESH, INDIA

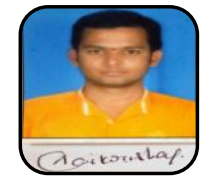

SAIKRISHNA LPPILLI, M.Tech,(Ph.D) Assistant Professor, Department of Civil Engineering, Aditya Institute of Technology And Management, ANDHRA PRADESH, INDIA

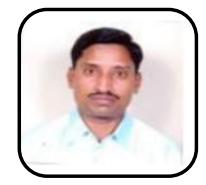

CHINTAGUNTI. VASUDEVA RAO M.Tech,Ph.D, Associate Professor, Department of Civil Engineering. Aditya Institute of Technology and Management, ANDHRA PRADESH, INDIA 